
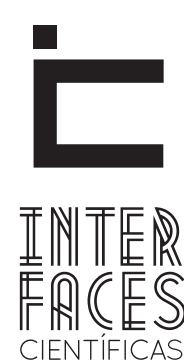

SAÚDE E AMBIENTE

\title{
SÍNDROME DE BURNOUT EM PROFISSIONAIS DE ENFERMAGEM DE UM GRANDE SERVIÇO DE URGÊNCIA DE SERGIPE
}

Fernanda Kelly Fraga Oliveira ${ }^{1}$

Fernanda Gomes de Magalhães Soares Pinheiro ${ }^{3}$
Mislene Silva Coutinho

\section{RESUMO}

A Síndrome de Burnout é a cronificação do estresse ocupacional causada por pressões no ambiente de trabalho decorrente do esgotamento físico e mental. A enfermagem é classificada como a quarta profissão mais estressante no setor público. 0 objetivo deste trabalho é identificar a Síndrome de Burnout e os possíveis preditores em profissionais de enfermagem de um grande pronto socorro público de Sergipe. 0 estudo descritivo com abordagem quantitativa com 27 profissionais de enfermagem atuantes no Pronto Socorro Área Verde-Trauma do Hospital de Urgência de Sergipe. Utilizou-se um questionário estruturado auto-aplicável, acrescido do instrumento Maslach Burnout Inventory. Verificou-se que $100 \%$ dos auxiliares de enfermagem tiveram um alto índice a exaustão emocional e um alto índice a baixa realização profissional, já os técnicos de enfermagem tiveram um alto índice $93,9 \%$ a baixa realização profissional e $60 \%$ alta exaustão emocional, seguido dos enfermeiros com $80 \%$ em alta exaustão emocional e $90 \%$ em baixa realização profissional. A dinâmica organizacional de um pronto socorro gera sobrecarga e tensão ocupacional, sendo necessário desenvolver táticas de reorganização do processo de trabalho, sugere-se que o sistema de classificação de risco já em uso nesse hospital possa estar alinhado às necessidades de horas de cuidados de enfermagem o que justificará o quantitativo de profissional ideal para uma assistência de qualidade com consequente melhoria da saúde do trabalhador. Propõe-se que as ações de enfermagem possam ser sistematizadas, com implementação da SAE, protocolos e rotinas, que estas possam ser desenvolvidas com apoio da educação permanente e táticas da gestão.

\section{PALAVRAS-CHAVE}

Enfermagem, doenças profissionais, esgotamento profissional. 


\section{ABSTRACT}

The burnout syndrome is the chronicity of occupational stress caused by pressures in the workplace due to the physical and mental exhaustion. Nursing is ranked as the fourth most stressful profession in the public sector. The objective of this work is to identify the Burnout Syndrome and possible predictors of nursing professionals of a large public ready rescue Sergipe. The descriptive study with a quantitative approach with 27 nurses working in the emergency room Green-Trauma area of the Emergency Hospital of Sergipe. We used a structured self-administered questionnaire, plus the instrument Maslach Burnout Inventory. It was found that $100 \%$ of nursing assistants had a high rate emotional exhaustion and a high rate low job satisfaction, as nursing technicians had a high rate $93.9 \%$ low job satisfaction and $60 \%$ high emotional exhaustion, followed by nurses with $80 \%$ for high emotional exhaustion and $90 \%$ in low job satisfaction. The organizational dynamics of a first aid generates overload occupational stress, being necessary to develop tactics reorganization of the work process, it is suggested that the risk rating system already in use in this hospital can be aligned with hours of nursing care needs which justifies the ideal professional for quantitative quality care with the improvement of workers' health. It is proposed that the nursing actions can be systematized, with implementation of the NAS, protocols and routines that they can be developed with the support of continuing education and tactical management.

\section{KEYWORDS}

Nursing. Occupational Diseases. Burnout Syndrome.

\section{RESUMEN}

El síndrome de Burnout es la cronicidad del estrés laboral causado por presiones en el lugar de trabajo, debido al agotamiento físico y mental. Enfermería se sitúa como la cuarta profesión más estresante en el sector público. El objetivo de este trabajo es identificar el síndrome de Burnout y posibles predictores de los profesionales de enfermería de un gran centro público de urgencias en Sergipe. El estudio es descriptivo, con abordaje cuantitativo, con 27 enfermeras que trabajan en la sala de urgencias de la Zona verde-Trauma del Hospital de Emergencia de Sergipe. Se utilizó un cuestionario auto estructurado, más el instrumento Maslach Burnout Inventory. Se verificó que el $100 \%$ de los auxiliares de enfermería tenía un elevado índice de cansancio emocional y una baja satisfacción laboral. Al paso que los técnicos de enfermería tenían una alta tasa de 93,9\%, y baja satisfacción laboral, y el $60 \%$ de alto agotamiento emocional, seguido de las enfermeras con el $80 \%$ para un elevado cansancio emocional y el $90 \%$ en baja satisfacción laboral. La dinámica de organización de una primera ayuda genera la carga de trabajo y la tensión, siendo necesario desarrollar tácticas de reorganización del proceso de trabajo, y se sugiere que el sistema de calificación de riesgo ya en uso en este hospital, se puede compaginar con horas de necesidades de atención de enfermería, lo que justifica el cuantitativo de profesional ideal, para una asistencia de calidad con la mejora de la salud de los trabajadores. Se propone que las acciones de enfermería pueden ser sistematizadas, con aplicación de los NAS, protocolos y rutinas que se pueden desarrollar con el apoyo de la educación continua y la gestión táctica.

\section{PALABRAS CLAVE}

Enfermería, Enfermedades Profesionales, Burnout. 


\section{INTRODUÇ̧̃̃o}

Inicialmente, na história o termo Burnout foi utilizado por Brandley, em 1969, mas ficou conhecido a partir de 1974 por meio de Freudenberger, psiquiatra, que trabalhava com toxicodependentes em Nova lorque. Ele observou que alguns voluntários apresentavam uma progressiva perda de energia até chegar ao esgotamento e sintomas de ansiedade e depressão, e descreveu que eram menos sensíveis, compreensivos, desmotivados e agressivos em relação aos doentes, com um comportamento distanciado e cínico e com tendência a culpá-los pelos seus próprios problemas (BORGES ET AL., 2002).

O nome Burnout deve origem no verbo inglês "to burn out” queimar-se por completo, consumir-se. Por meio de seu cansaço e frustração que o trabalho lhe trazia concluiu-se que esta síndrome é um estado em que ocorre o esgotamento físico e mental ligado à vida profissional (FREUDENBERGER, 1974).

O local de trabalho influencia sensivelmente o grau de realização pessoal no trabalho e a possibilidade de desenvolver estresse e, possivelmente, Burnout a partir de um ambiente que exerça pressão sobre os indivíduos, nesse sentido, a enfermagem cumpre carga horária exaustiva com baixa remuneração, o que pode favorecer ao desenvolvimento de preditores da patologia. Os profissionais de enfermagem que desempenham ações em serviços de alta complexidade e eixos de pacientes críticos estão mais propensos a desenvolver Burnout, uma vez que convivem com situações estressoras, requerendo muito esforço físico e mental (BITTENCOURT, 2012).

De acordo com Ferreira Júnior (2000), na atenção à saúde dos trabalhadores, são indissociáveis as ações preventivas de promoção e proteção da saúde, assistência, ou recuperação e reabilitação. Diz ainda que, no mundo da saúde e trabalho, as coisas são mais complexas, ver-se-á, por exemplo, que as prin- cipais profissões de saúde pouco ou nada se preparam, habitualmente, para lidar com a especificidade dos problemas dos trabalhadores. Essa observação é válida principalmente para médicos e enfermeiros, no Brasil e na maior parte do mundo.

Dessa forma, Maslach (1981) relata que esta é uma situação que afeta, com $1 / 4$ de maior frequência, pessoas que, em decorrência de sua profissão, mantêm um contato direto e contínuo com outros seres humanos. Ainda de acordo com Maslach (1998), a patologia pode ser um fator de proteção, mas representa risco de desumanização, constituindo a dimensão interpessoal de Burnout.

Contudo, Borges e outros autores (2002) refletem que o Burnout pode ser abordado sob duas perspectivas: a clínica e a psicossocial. A primeira define a patologia como um estado de esgotamento, decepção e perda do interesse pelo trabalho, que surge em profissionais que estão em contato direto com pessoas, como uma consequência do contato diário. A segunda entende a síndrome como um processo que se desenvolve na interação de características do ambiente de trabalho e características pessoais.

Para Ballone e Moura (2008), a síndrome pode ser definida como uma das consequências mais marcantes do estresse profissional, sendo caracterizada como uma reação à tensão emocional crônica gerada a partir do contato direto, excessivo e estressante com o trabalho. Essa patologia faz com que a pessoa diminua o interesse pelo trabalho, de forma que as relações e os acontecimentos deixem de ter importância e qualquer esforço pessoal pareça ser inútil.

É fundamental a proposição de novas pesquisas que investiguem e possam oferecerer outras possibilidades interventivas, tendo em vista que, há o surgimento de novas formas de adoecimento mal caracterizadas, como o estresse e a fadiga física e mental e outras manifestações de sofrimento relacionadas ao trabalho. Configura, portanto, situações que exigem 
mais pesquisas e conhecimentos para que se possam traçar propostas coerentes e efetivas de intervenção (BRASIL, 2001).

A profissão enfermagem foi classificada pela Health Education Authority como a quarta profissão mais estressante, no setor público, e, ainda que o exercício da profissão de enfermagem requeira boa saúde física e mental, raramente os enfermeiros recebem a proteção social adequada para o seu desempenho. $\mathrm{Ou}$ seja, apesar de exercerem atividades estafantes, muitas vezes em locais inadequados, não recebem a proteção e atenção necessárias para evitar os acidentes e as doenças decorrentes das atividades (MUROFUSE; ABRANCHES; NAPOLEÃO, 2005).

Os transtornos mentais e comportamentais em trabalhadores de enfermagem constituíram a segunda causa da demanda de atenção prestada pelo Serviço de Medicina do Trabalho. 0 número reduzido de profissionais de enfermagem está diretamente relacionado ao excesso de trabalho. Além disso, a insatisfação com o salário agrava a situação, levando os profissionais a possuir outro vínculo empregatício com consequente aumento na carga horária mensal (JODAS; HADDAD, 2008).

Portanto, Benevides-Pereira (2002) relata que a enfermagem requer uma série de atividades que necessitam forçadamente de um controle mental e emocional, muito maior que em outras profissões. Eles têm que manejar com pacientes em estado grave; devem compartilhar com o enfermo e seus familiares a angústia, a dor, a depressão e o medo de padecerem.

A partir dessas considerações justifica-se a pertinência do artigo, que tem como objetivo identificar a Síndrome de Burnout e os possíveis preditores em profissionais de enfermagem do grande pronto socorro público de Sergipe, caracterizando os profissionais de saúde quanto à idade, o sexo, a profissão, o estado civil, filhos, número de horas trabalhadas, titulação; descrever os preditores do estresse decorrentes do trabalho, relacionado à quantidade de vínculos empregatícios e identificar a categoria profissional e 0 índice dos preditores da Síndrome de Burnout.

\section{CASUÍSTICA E METÓDOS}

Pesquisa de caráter exploratório e descritivo com abordagem quantitativa, sendo a população de estudo composta por 27 (vinte e sete) trabalhadores de enfermagem sendo: 2 (dois) auxiliares de enfermagem, 15 (quinze) técnicos de enfermagem e 10 (dez) enfermeiros.

O local do estudo foi o Pronto Socorro-PS, Área Verde-Trauma do Hospital de Urgência de Sergipe Governador João Alves Filho (HUSE), com coleta de dados no mês de maio de 2012, nos três turnos de trabalho, manhã, tarde e noite. A pesquisa foi iniciada após autorização da instituição em estudo e posterior aprovação do Comitê de Ética em Pesquisa da Universidade Tiradentes, sob protocolo $n^{0} 080412$.

O complexo hospitalar possui atualmente 1.228 profissionais de enfermagem, entre enfermeiros, técnicos e auxiliares. Com um atendimento médio de 14 mil pacientes por mês somente nos setores de urgência/emergência. No meio hospitalar a Enfermagem representa mais de um terço dos profissionais que atuam nestes estabelecimentos e segundo o Ministério da Saúde, abrange mais de 650 mil profissionais da área em todo o país (SERGIPE, 2012).

0 atendimento é organizado de acordo com o protocolo de classificação de risco para o acolhimento das vítimas que divide o pronto socorro em áreas por cores que classificam a prioridade do atendimento aos pacientes (BRASIL, 2004). O HUSE é o maior Hospital Público de Sergipe, com o maior Pronto Socorro do Estado, e principal porta de entrada do Sistema Único de Saúde (SUS) para os casos de alta complexidade. Dessa forma o PS do HUSE é composto pelas Áreas Vermelha, Verde, Azul e Amarela. A Área Verde é divi- 
dida em Verde-Clínica e Verde-Trauma, a Área Verde-Trauma é dividida em três setores: corredor de sutura; aerosol (observação feminina) e observação central I e central II (observação masculina). Ainda assim, a Área Verde-Trauma dispõe de diversas especialidades de atendimento como: ortopedia, neurologia, neurocirurgia, cirurgia geral, torácica, vascular, bucomaxilo. A Unidade referida é composta por 50 (cinquenta) leitos, com um atendimento médio de 90 (noventa) pacientes ao dia, independente da quantidade de leitos, visto que esta é uma instituição porta aberta.

Para a coleta de dados foi utilizado um questionário estruturado autoaplicável, verificando dados socioeconômicos, dados pessoais, atividades de lazer, fatores preditores e sintomas somáticos, conforme proposto em um estudo (JODAS; HADDAD, 2008), que registra os dados profissionais, informações sobre lazer, fatores organizacionais, preditores de Burnout e alguns sintomas somáticos relacionados com a doença, além do instrumento Maslach Burnout Inventory (MBI), criado por Maslach \& Jackson (1981), sendo traduzido e adaptado no Brasil por Lautert (1995) para avaliar a incidência da Síndrome de Burnout nos profissionais de enfermagem da referida Unidade de Saúde (Anexo A).

A forma de pontuação de todos os itens pesquisados segue a escala do tipo Likert que varia de zero a seis, sendo: $\underline{0}$ nunca, $\underline{1}$ uma vez ao ano ou menos, $\underline{2}$ uma vez ao mês ou menos, $\underline{3}$ algumas vezes no mês, $\underline{4}$ uma vez por semana, $\underline{5}$ algumas vezes por semana, $\underline{6}$ todos os dias. Os dados coletados nesse estudo foram analisados, utilizando o programa Microsoft Excel 2010, confrontados com artigos científicos e obras literárias referentes ao tema em estudo e representados por meio gráficos e tabelas.

Para apreciação dos dados relativos ao instrumento do $\mathrm{MBI}$, realizou-se a somática de cada dimensão (exaustão emocional, despersonalização e baixa realização profissional). Os valores obtidos foram comparados com os valores de referência do Núcleo de Estudos Avançados sobre a Síndrome de Burnout-NEPASB, apresentados na Tabela 1.

Tabela 1 - Valores da escala do MBI desenvolvidos pelo Núcleo de Estudos Avançados sobre a Síndrome de Burnout, 2001

Dimensões

Baixo

Exaustão Emocional

Despersonalização

\section{Baixa Realização profissional 0 - 33}

\section{Pontos de corte}

Médio Alto

$\begin{array}{lll}0-15 & 16-25 & 26-54 \\ 0-02 & 03-08 & 09-30\end{array}$

$34-42 \quad 43-48$

Fonte: Benevides-Pereira, 2001. 
A amostra é do tipo não probabilístico por acessibilidade constituída pelos 27 profissionais de enfermagem, que atenderam aos critérios de inclusão como ser profissional de enfermagem, enfermeiro, técnico ou auxiliar de enfermagem, com vinculo empregatício fixo no hospital explícito no setor PS, Área Verde-Trauma que concordaram com a pesquisa, assinando o Termo de Consentimento Livre e Esclarecido (TCLE) e com disponibilidade de tempo e interesse em participar da coleta de dados. Foram exclusos da pesquisa os membros da equipe de enfermagem que estavam ausentes (férias ou atestado médico) e os que estavam cobrindo outro profissional, não lotados no setor em estudo.

\section{RESULTADOSE DISCUSSÃO}

A categoria profissional dos pesquisados da Área Verde-Trauma do HUSE em Aracaju/SE em 2012 era composta por 27 (vinte e sete) trabalhadores de enfermagem, $7 \%(\mathrm{~N}=2)$ eram auxiliares de enfermagem, 56\% $(\mathrm{N}=15)$ técnicos de enfermagem e $37 \%(\mathrm{~N}=10)$ eram enfermeiros.

Dados de 2010 previam que Sergipe dispunha de 11.614 profissionais de enfermagem, com 1.767 enfer- meiros, 3.584 técnicos de enfermagem e 6.211 auxiliares de enfermagem, diferente do que identificado neste estudo ocorreu à prevalência de técnicos de enfermagem seguido dos enfermeiros. No cenário da pesquisa é utilizado o chamado Sistema de Classificação de Pacientes (SCP) que permite considerar a gravidade do paciente internado no cálculo de pessoal de enfermagem, assim o dimensionamento ideal pode garantir uma qualidade aos cuidados a pacientes e trabalhadores.

Conforme os dados da Tabela 1, os profissionais de enfermagem, na grande maioria, são do sexo feminino $81 \%$, sendo que $64 \%$ não mantinham união estável e $56 \%$ não possuíam filhos. A faixa etária predominou entre 20 - 35 anos de idade $74 \%$, com média de 33 anos, extremos de 24 e 52 anos. Para tanto, Cushway \& Tyler (1996), apontam que mulheres apresentam escores mais elevados que homens para exaustão emocional, enquanto estes últimos apresentam maior tendência à despersonalização. A dupla jornada de trabalho a que as mulheres geralmente são submetidas é apontada como fator que contribui para maiores níveis de exaustão emocional, atribui-se ainda ao casamento ou à situação de companheiro estável e ao fato de ter filhos uma menor propensão ao Burnout.

Tabela 1 - Distribuição das características sociodemográficas dos profissionais de enfermagem pesquisados da Área Verde Trauma do HUSE em Aracaju/Se - 2012

\begin{tabular}{|c|c|c|c|}
\hline & Variável & $\%$ & $n$ \\
\hline Idade & $\begin{array}{l}20-35 \\
36-45 \\
46-55\end{array}$ & $\begin{array}{c}74 \\
19 \\
7\end{array}$ & $\begin{array}{c}20 \\
5 \\
2\end{array}$ \\
\hline Sexo & $\begin{array}{l}\text { Masculino } \\
\text { Feminino }\end{array}$ & $\begin{array}{l}19 \\
81\end{array}$ & $\begin{array}{c}5 \\
22\end{array}$ \\
\hline Estado civil & $\begin{array}{l}\text { Solteiro } \\
\text { Casado } \\
\text { Divorciado }\end{array}$ & $\begin{array}{c}64 \\
33 \\
3\end{array}$ & $\begin{array}{c}17 \\
9 \\
1\end{array}$ \\
\hline Filhos & $\begin{array}{l}\text { Sim } \\
\text { Não }\end{array}$ & $\begin{array}{l}44 \\
56\end{array}$ & $\begin{array}{l}12 \\
15 \\
\end{array}$ \\
\hline
\end{tabular}

Fonte: Dados da Pesquisa, 2012. 
Algumas pesquisas relatam maior propensão ao Burnout nas pessoas que possuem nível educacional mais elevado. Nesses grupos, as pontuações de Exaustão Emocional e Despersonalização encontram-se mais elevadas que em grupos com menos grau de escolaridade, assim como para a escala de Realização Profissional, em que os com menos escolaridade sentem-se menos realizados. A realização pessoal no trabalho pode estar relacionada ao status e o reconhecimento de que gozam muitas profissões de nível superior (MASLACH; LEITER, 1997).
Sendo assim, dentre os 27 profissionais pesquisados, apenas $22,2 \%$ possuem especialização, $29,7 \%$ possuem graduação e $48,1 \%$ o ensino médio.

Na descrição da Tabela 2, nota-se a situação de trabalho em que os profissionais na sua maioria $63 \%$ encontram-se exercendo um cargo celetista (CLT), com horas trabalhadas entre 30 a 48 horas $55 \%$ dos pesquisados, sendo a média de 36 horas semanais. Todavia $45 \%$ possuíam carga horária superior a 60 horas semanais, justificados pelo acúmulo de vínculo empregatício em outra instituição, totalizando $41 \%$ dos sujeitos.

Tabela 2 - Distribuição das características do trabalho dos profissionais de enfermagem pesquisados da Área Verde Trauma do HUSE em Aracaju/Se - 2012

\begin{tabular}{ccc}
\hline Variável & $\%$ & $\mathbf{N}$ \\
\hline Horas trabalhadas & 55 & 15 \\
De 30h a 48h & 30 & 8 \\
De 49h a 72h & 15 & 4 \\
De73h a 80h & & \\
CLT & 63 & 17 \\
Estatutário & 37 & 10 \\
\hline Vínculo empregatício do trabalho & & \\
Sim & 41 & 11 \\
Não & 59 & 16 \\
\hline
\end{tabular}

Fonte: Dados da Pesquisa, 2012. 
O número reduzido de profissionais de enfermagem está diretamente relacionado ao excesso de trabalho. Para Murofuse, Abranches e Napoleão (2005), a insatisfação com o salário agrava a situação, levando os profissionais a possuir outro vínculo empregatício com consequente aumento na carga horária mensal.

Para São Paulo (2004), a readaptação funcional é definida como investidura do servidor em cargo ou atribuição e responsabilidades compatíveis com a limitação que tenha sofrido em sua capacidade física ou mental verificada em inspeção médica. Assim, esta é uma das principais causas de insatisfação profissional e de adoecimento físico e mental, portanto no estudo apenas $4 \%$ foi readaptado.

Das faltas justificadas no mês de maio de 2012, $70,3 \%(\mathrm{~N}=19)$ não apresentaram nenhuma falta, $11,2 \%$ $(\mathrm{N}=3)$ uma falta e $18,5 \%(\mathrm{~N}=5)$ apresentaram mais de duas faltas justificadas. Observa-se então que o número de faltas justificadas neste estudo não houve relação com a Síndrome de Burnout, pois essa se manifesta por meio de quatro classes sintomatológicas, dentre elas a comportamental, identificada quando o indivíduo apresenta-se negligente no trabalho, com irritabilidade oca- sional ou instantânea, incapacidade para se concentrar, aumento das relações conflitivas com os colegas, longas pausas para o descanso e cumprimento irregular do horário de trabalho (GUIMARÃES; CARDOSO, 2004).

Quanto às atividades físicas praticadas pelos pesquisados, observa-se que $52 \%$ não praticam nenhum tipo de atividade física, porém $48 \%$ afirmaram positivamente.

Para Bittencourt (2012), a Síndrome de Burnout quando não cuidada pode levar até a morte, afirmando que pequenas mudanças no cotidiano podem ser fortes aliadas, tais como: alimentação balanceada, praticar atividades físicas, ter um hobby, manter relações sociais e integração familiar. A atividade física e hábitos saudáveis favorecem a qualidade de vida, diminuindo agravos à saúde como obesidade, hipertensão e estresse.

De acordo com World Health Organization (1998), para a enumeração dos fatores de risco, para o desenvolvimento da patologia, são levadas em consideração quatro dimensões: a organização, o indivíduo, o trabalho e a sociedade. Nos dados da Tabela 3, são apresentados os fatores preditores-FP, aqueles que predizem o surgimento da síndrome.

Tabela 3 - Distribuição dos fatores preditores relacionados à variável organizacional dos profissionais de enfermagem pesquisados da Área Verde Trauma do HUSE em Aracaju/Se - 2012

\section{Pontuação (\%)}

\begin{tabular}{|c|c|c|c|c|c|c|}
\hline Iunca & $\begin{array}{l}\text { Uma } \\
\text { vezl }\end{array}$ & $\begin{array}{l}\text { Uma } \\
\text { vez/ }\end{array}$ & $\begin{array}{c}\text { Algumas } \\
\text { vezes/ }\end{array}$ & $\begin{array}{c}\text { Uma } \\
\text { vez/ }\end{array}$ & $\begin{array}{c}\text { Algumas } \\
\text { vezes/ }\end{array}$ & $\begin{array}{c}\text { Todos } \\
\text { os }\end{array}$ \\
\hline & ano & mês & Mês & semar & semana & \\
\hline
\end{tabular}

\begin{tabular}{ccccccccc}
$\begin{array}{c}\text { Fatores } \\
\text { Preditores }\end{array}$ & 0 & 1 & 2 & 3 & 4 & 5 & 6 \\
& & & & & & & & \\
1. FP1 & 11,1 & 3,7 & 3,7 & 18,5 & 7,4 & 29,7 & 25,9 & 100 \\
\hline
\end{tabular}




\begin{tabular}{lcccccccc} 
& Nunca & $\begin{array}{c}\text { Uma } \\
\text { vez/ } \\
\text { ano }\end{array}$ & $\begin{array}{c}\text { Uma } \\
\text { vez/ } \\
\text { mês }\end{array}$ & $\begin{array}{c}\text { Algumas } \\
\text { vezes/ }\end{array}$ & $\begin{array}{c}\text { Uma } \\
\text { vez/ }\end{array}$ & $\begin{array}{c}\text { Algumas } \\
\text { vezes/ } \\
\text { semana }\end{array}$ & $\begin{array}{c}\text { Todos } \\
\text { os } \\
\text { dias }\end{array}$ & Total \\
\hline 2. FP2 & 11,1 & 3,7 & 0 & 14,9 & 3,7 & 33,3 & 33,3 & 100 \\
3. FP3 & 63 & 18,5 & 3,7 & 14,8 & 0 & 0 & 0 & 100 \\
4. FP4 & 70,4 & 22,2 & 0 & 3,7 & 3,7 & 0 & 0 & 100 \\
5. FP5 & 18,5 & 11,1 & 18,5 & 29,7 & 7,4 & 7,4 & 7,4 & 100 \\
6. FP6 & 11,1 & 7,4 & 7,4 & 22,2 & 11,1 & 11,1 & 29,7 & 100 \\
\hline
\end{tabular}

Legenda: FP1-As atividades que desempenho que exigem mais tempo do que posso fazer em um dia de trabalho. FP2-Sinto que posso controlar os procedimentos e atendimentos para os quais sou designado na instituição de trabalho. FP3-A instituição onde atuo reconhece e recompensa os diagnósticos precisos, atendimentos e procedimentos realizados pelos seus funcionários. FP4-Percebo que a instituição onde atuo o profissional é sensível aos funcionários, isto é, valoriza e reconhece o trabalho desenvolvido, assim como investe e incentiva o desenvolvimento profissional dos seus funcionários. FP5-Percebo de forma evidente que existe respeito nas relações internas da instituição (na equipe de trabalho e entre coordenação de seus funcionários). FP6-Na instituição onde atuo tenho a oportunidade de realizar um trabalho que considero importante.

Verifica-se que $29,7 \%$ responderam que numa frequência de algumas vezes na semana as atividades desempenhadas exigem mais tempo do que é possível realizar em um dia de trabalho, outros 25,9\% afirmaram que essa frequência acontece todos os dias. Para Murofuse, Abranches e Napoleão (2005) o excesso de trabatho pode produzir gradualmente a exaustão emocional, criativa ou física, reduzindo sua energia no que diz respeito à eficiência, saúde e bem-estar. Quando o trabalho é classificado como estressante, características do PS, os sintomas de Burnout são respostas esperadas.
Referente ao controle do procedimento e atendimento (FP2), 11,1\% dos profissionais ressaltaram que nunca não podem controlar, porém 33,33\% relatam que podem controlar os procedimentos e atendimentos algumas vezes por semana e todos os dias.

De acordo com Tamayo e Tróccoli (2002) aspectos organizacionais como sobrecarga de trabalho, falta de controle, recompensa insuficiente e conflito de valores podem influenciar a qualidade do trabalho, em caráter maior que comparado ao relacionamento com o paciente.

O FP3 alude ao reconhecimento e recompensa da instituição para os diagnósticos precisos e atendimentos e procedimentos realizados pelos seus funcionários, $63 \%$ dos entrevistados relataram que nunca houve este reconhecimento e $18,5 \%$ responderam que o mesmo acontece uma vez ao ano.

0 trabalhador que atua em instituições hospitalares está exposto a diferentes estressores ocupacionais que afetam diretamente o seu bem-estar. Dentre eles, podemos citar as longas jornadas de trabalho, o número insuficiente de pessoal, a falta de reconhecimento profissional, assim como o contato constante com o sofrimento, com a dor e, muitas vezes, com a morte. 0 desempenho desses profissionais envolve uma série de atividades que necessitam de um con- 
trole mental e emocional muito maior que em outras profissões (BENEVIDES-PEREIRA, 2002).

O FP4 indica a valorização e reconhecimento do trabalho desenvolvido pelo profissional, o incentivo e investimento no desenvolvimento profissional, logo $70,4 \%$ dos profissionais contrapuseram que nunca foi demonstrada tal valorização, reconhecimento, incentivo e investimento.

A instituição hospitalar possui uma estrutura organizacional complexa quanto aos profissionais, papéis, estrutura, divisão de trabalho, metas, hierarquia e normas que a regulam. Há uma prática profissional voltada, quase que exclusivamente para a eficácia do atendimento ao paciente, e muitas vezes, percebe-se uma menor valorização das condições de trabalho essenciais para a saúde do trabalhador, que permanecem expostos por um período prolongado a situações que exigem alta demanda emocional (MASLACH \& JACKSON, 1981).

De acordo com o FP5 que refere respeito nas relações internas da instituição, entre a equipe de trabalho e a coordenação, $29,7 \%$ dos profissionais contestaram que isso ocorre algumas vezes no mês e $7,4 \%$ responderam que acontece uma vez na semana, algumas vezes na semana e todos os dias.

Neste sentido, Lautert (1997), explana que o rápido desenvolvimento tecnológico, a divisão e expansão das especialidades médicas determinam o hospital como um complexo sistema de divisão do trabalho, com elevada hierarquia de autoridade, com canais formais de comunicação e um grande conjunto de regras e normas para seu funcionamento. Assim, existem neste contexto duas linhas paralelas de autoridade: a administrativa e a profissional, sendo frequente o surgimento de conflitos devido a diferentes conjuntos de valores. Este confronto, que se repete continuamente, é gerador de ansiedade e estresse, que pode contribuir para a baixa motivação profissional em profissionais da saúde.
O FP6 examinou quanto à oportunidade de realizar um trabalho na instituição que considera importante, $29,7 \%$ dos profissionais expuseram que têm a oportunidade de realizar o mesmo todos os dias e $7,4 \%$ replicaram que realizam uma vez ao mês e uma vez ao ano. Quando o indivíduo realiza suas atividades com satisfação e amor, quando a faz com dedicação, este realiza sua função com desempenho e qualidade, aqueles que revelam insatisfação com as suas atividades realizadas, tem consequentemente uma maior predisposição para gerar conflito, estresse e possivelmente Burnout.

Para Benevides-Pereira (2002), algumas vezes o trabalho conflita com valores pessoais, com as noções éticas incorporadas, e o profissional sente-se impelido a atuar em desacordo com seus princípios, gerando desconforto e mal-estar. Além disso, quanto maior o nível de controle e participação nas decisões, maior a satisfação no trabalho e menor chance de ocorrência de Burnout.

A Tabela 4 apresenta a distribuição percentual da sintomatologia física associada ao trabalho, apresentada pelos profissionais de enfermagem pesquisados. Para Bittencourt (2012) o principal sintoma da Síndrome de Burnout é a sensação de ter sido consumido pelo estresse, de estar esgotado e sem energia.

Vários outros sintomas são comuns, como sono ruim; cansaço; dores no corpo; lapsos de memória; dificuldade de concentração; irritabilidade; desesperança; tristeza e transtorno de humor; esgotamento profissional que corresponde ao colapso físico e mental; avaliação negativa de si mesmo; depressão e insensibilidade com relação a quase tudo e todos; descaso com necessidades pessoais (comer, dormir e sair com os amigos); recalque de conflitos, em que o portador percebe que algo não vai bem, mas não enfrenta o problema; discriminação pelos colegas de trabalho. Cinismo e agressão, também, são bastante evidentes. 
Tabela 4 - Distribuição dos fatores preditores relacionados à variável organizacional dos profissionais de enfermagem pesquisados da Área Verde Trauma do HUSE em Aracaju/Se - 2012

\begin{tabular}{|c|c|c|c|c|c|c|c|}
\hline Sintomas & Nunca & $\begin{array}{l}\text { Uma vez/ } \\
\text { ano }\end{array}$ & $\begin{array}{l}\text { Uma vez/ } \\
\text { mês }\end{array}$ & $\begin{array}{l}\text { Algumas } \\
\text { vezes/ } \\
\text { mês }\end{array}$ & $\begin{array}{l}\text { Uma } \\
\text { vez/ } \\
\text { semana }\end{array}$ & $\begin{array}{l}\text { Algumas } \\
\text { vezes/ } \\
\text { semana }\end{array}$ & $\begin{array}{l}\text { Todos } \\
\text { os dias }\end{array}$ \\
\hline Cefaleia & $14,8 \%$ & $11,1 \%$ & $11,1 \%$ & $22,2 \%$ & $3,7 \%$ & $29,6 \%$ & $7,4 \%$ \\
\hline Irritabilidade fácil & $14,8 \%$ & $3,7 \%$ & $3,7 \%$ & $18,5 \%$ & $3,7 \%$ & $29,6 \%$ & $25,9 \%$ \\
\hline Perda/Excesso de apetite & $44,4 \%$ & $3,7 \%$ & 0 & $22,2 \%$ & $7,4 \%$ & $18,5 \%$ & $3,7 \%$ \\
\hline Pressão arterial alta & $62,9 \%$ & $7,4 \%$ & $7,4 \%$ & $14,8 \%$ & 0 & 0 & $7,4 \%$ \\
\hline Dores nos ombros/nuca & $14,8 \%$ & $11,1 \%$ & $3,7 \%$ & $22,2 \%$ & $3,7 \%$ & $33,3 \%$ & $11,1 \%$ \\
\hline Dor no peito & $59,2 \%$ & $7,4 \%$ & $14,8 \%$ & $7,4 \%$ & $3,7 \%$ & $3,7 \%$ & $3,7 \%$ \\
\hline Dificuldade com o sono & $44,4 \%$ & $7,4 \%$ & $3,7 \%$ & $3,7 \%$ & $3,7 \%$ & $29,6 \%$ & $7,4 \%$ \\
\hline $\begin{array}{l}\text { Sentimento de cansaço } \\
\text { mental }\end{array}$ & $11,1 \%$ & 0 & $7,4 \%$ & $25,9 \%$ & $11,1 \%$ & $18,5 \%$ & $25,9 \%$ \\
\hline Dificuldades sexuais & $55,5 \%$ & $3,7 \%$ & $7,4 \%$ & $25,9 \%$ & $3,7 \%$ & 0 & $3,7 \%$ \\
\hline $\begin{array}{l}\text { Pouco tempo para } \\
\text { si mesmo }\end{array}$ & $3,7 \%$ & 0 & $3,7 \%$ & $22,2 \%$ & $7,4 \%$ & $37 \%$ & $25,9 \%$ \\
\hline Fadiga generalizada & $22,2 \%$ & $3,7 \%$ & $11,1 \%$ & $14,8 \%$ & $14,8 \%$ & $22,2 \%$ & $11,1 \%$ \\
\hline Pequenas infecções & $33,3 \%$ & $18,5 \%$ & $29,5 \%$ & $11,1 \%$ & 0 & $3,7 \%$ & $7,4 \%$ \\
\hline $\begin{array}{l}\text { Aumento do consumo de } \\
\text { bebidas, cigarro/substância } \\
\text { química }\end{array}$ & $77,7 \%$ & $3,7 \%$ & $11,1 \%$ & $3,7 \%$ & $3,7 \%$ & 0 & 0 \\
\hline $\begin{array}{l}\text { Dificuldade de memória e } \\
\text { concentração }\end{array}$ & $e_{22,2 \%}$ & $7,4 \%$ & $25,9 \%$ & $14,8 \%$ & $3,7 \%$ & $18,5 \%$ & $7,4 \%$ \\
\hline
\end{tabular}




\begin{tabular}{|c|c|c|c|c|c|c|c|}
\hline Sintomas & Nunca & $\begin{array}{l}\text { Uma vez/ } \\
\text { ano }\end{array}$ & $\begin{array}{l}\text { Uma vez/ } \\
\text { mês }\end{array}$ & $\begin{array}{l}\text { Algumas } \\
\text { vezes/ } \\
\text { mês }\end{array}$ & $\begin{array}{l}\text { Uma } \\
\text { vez/ } \\
\text { semana }\end{array}$ & $\begin{array}{l}\text { Algumas } \\
\text { vezes/ } \\
\text { semana }\end{array}$ & $\begin{array}{l}\text { Todos } \\
\text { os dias }\end{array}$ \\
\hline $\begin{array}{l}\text { Problemas } \\
\text { gastrointestinais }\end{array}$ & $37 \%$ & $22,2 \%$ & $14,8 \%$ & $7,4 \%$ & $7,4 \%$ & $7,4 \%$ & $3,4 \%$ \\
\hline Problemas alérgicos & $55,5 \%$ & $25,9 \%$ & $7,4 \%$ & $7,4 \%$ & 0 & $3,4 \%$ & 0 \\
\hline $\begin{array}{l}\text { Estado de aceleração } \\
\text { contínua }\end{array}$ & $33,3 \%$ & $7,4 \%$ & $14,8 \%$ & $18,5 \%$ & $3,4 \%$ & $14,8 \%$ & $7,4 \%$ \\
\hline $\begin{array}{l}\text { Sente-se sem vontade de } \\
\text { começar nada }\end{array}$ & $22,2 \%$ & $11,1 \%$ & $18,5 \%$ & $18,5 \%$ & $7,4 \%$ & $7,4 \%$ & $14,8 \%$ \\
\hline Perda do senso de humor & $18,5 \%$ & $3,4 \%$ & $14,8 \%$ & $29,6 \%$ & $7,4 \%$ & $18,5 \%$ & $7,4 \%$ \\
\hline Gripes e resfriados & $22,2 \%$ & $22,2 \%$ & $40,7 \%$ & $14,8 \%$ & 0 & 0 & 0 \\
\hline Perda do desejo sexual & $62,9 \%$ & $14,8 \%$ & $7,4 \%$ & $7,4 \%$ & 0 & $3,4 \%$ & $3,4 \%$ \\
\hline
\end{tabular}

Fonte: Dados da Pesquisa, 2012.

Percebe-se que, a presença dos sintomas comportamentais no que se acena à Tabela 4 em a relação de irritabilidade fácil, sentimento de cansaço mental e pouco tempo para si, observou-se que $25,9 \%$ dos profissionais estudados percebem este sentimento todos os dias.

Entre os pesquisados $14,8 \%$ responderam que todos os dias sentem-se sem vontade de começar nada e ainda $11,1 \%$ sentem dores nos ombros/nuca e fadiga generalizada. Entretanto, $77,7 \%$ não sentiram aumento do consumo de bebidas, cigarro/substância química, 62,9\% não tiveram pressão arterial alta e não perderam o desejo sexual.

Assim, por meio dos resultados da pesquisa foi presumível identificar a realidade em que se encontram os profissionais do PS Área Verde-Trauma (HUSE), sendo possível perceber que o ambiente de trabalho e as condições organizacionais são fundamentais para o aparecimento da patologia, tendo seu desenvolvimento acelerado quando o profissional se depara com os problemas que surgem na rotina profissional, intensificando a sensação de inadequação na empresa e o sofrimento emocional, que consequentemente desencadeiam para o advento de sintomas físicos já que o emocional afetou a saúde como um todo.

A avaliação da Síndrome de Burnout é realizada por meio do questionário "Maslach Burnout Inventor" (MBI), de Maslach e Jackson, sendo um instrumento autoaplicável utilizado em todo o mundo e que avalia o desgaste profissional. De acordo com Benevides-Pereira (2002), a versão atual é formada por 22 (vinte e dois) itens, sendo que as questões de 1-9 identificam o nível de exaustão emocional (EE); 10-17 estão relacionadas à baixa realização profissional (BRP) e as questões 18-22 estão relacionadas à despersonalização (DE).

Considera-se com Burnout uma pessoa que apresente altas pontuações em EE e DE, associadas a baixos valores em BRP. Existem três versões do MBI, a Human Services Survey (HSS), que avalia o Burnout em profissionais de serviços humanos (médicos, en- 
fermeiros, psicólogos e outros), a Educators Survey (ED), para os educadores (professores); e a General Survey (GS), selecionado para todos os trabalhadores, em geral. Os estudantes de graduação e técnico da área da saúde são classificados no HSS. A Tabela 5 apresenta o percentual das médias e níveis das subescalas em relação às três dimensões da Síndrome de Burnout por categoria profissional.

Tabela 5 - Médias e níveis das subescalas de MBI por categoria profissional

\begin{tabular}{|c|c|c|c|c|c|c|c|c|c|}
\hline & & EE & & & BRP & & & DE & \\
\hline & Baixo & Médio & Alto & Baixo & Médio & Alto & Baixo & Médio & Alto \\
\hline $\begin{array}{l}\text { Auxiliar de } \\
\text { Enfermagem }\end{array}$ & 0 & 0 & $100 \%$ & 0 & 0 & $100 \%$ & $100 \%$ & 0 & 0 \\
\hline $\begin{array}{l}\text { Técnico de } \\
\text { Enfermagem }\end{array}$ & $13,33 \%$ & $26,67 \%$ & $60 \%$ & $6,7 \%$ & 0 & $93,3 \%$ & $100 \%$ & 0 & 0 \\
\hline Enfermeiro & 0 & $20 \%$ & $80 \%$ & 0 & $10 \%$ & $90 \%$ & $100 \%$ & 0 & 0 \\
\hline
\end{tabular}

Fonte: Dados da Pesquisa, 2012.

A Exaustão Emocional é caracterizada pela falta ou carência de energia, entusiasmo e por sentimento de esgotamento de recursos. A Baixa Realização Profissional caracteriza-se por uma tendência do trabalhador em se autoavaliar de forma negativa, sentindo-se infeliz e insatisfeito com seu desenvolvimento profissional. Já a Despersonalização faz com que o profissional passe a tratar os clientes, colegas e a organização como objetos. 0 manual do MBI traz, como princípio para o diagnóstico de Burnout, a obtenção de nível alto para exaustão emocional e despersonalização e nível baixo para realização profissional. Portanto, o enquadramento do profissional nesses três critérios dimensionais indica a manifestação da síndrome.

O risco de desenvolvimento dessa síndrome será determinado após a análise de todas as dimensões, a fim de mensurar a possibilidade de o pesquisado manifestar a doença (MENEGAZ, 2004). Outros itens como fatores preditores e sintomas somáticos foram analisados por porcentagem simples em relação à frequência relatada pelo examinado.
Tratando-se dos valores mais encontrados de cada dimensão com relação aos limites estabelecidos pelo NEPASB verificou-se que $100 \%$ dos auxiliares de enfermagem da pesquisa tiveram um alto índice a exaustão emocional e um alto índice a baixa realização profissional, já os técnicos de enfermagem tiveram um alto índice $93,9 \%$ a baixa realização profissional e $60 \%$ alta exaustão emocional, em seguida os enfermeiros com $80 \%$ em alta exaustão emocional e $90 \%$ em baixa realização profissional, as categorias estudadas obtiveram na subescala de despersonalização profissional 100\%, alcançando um baixo índice.

Assim, ao relacionar as três dimensões foi averiguado que o universo pesquisado apresentou preditores da síndrome, já que como resultado, foi obtido justamente o que os autores colocam como indicativo de Burnout, pontuações elevadas em exaustão emocional e baixa realização profissional e nível baixo para a despersonalização nas três categorias. 


\section{CONCLUSÃO}

Ao reconhecer a saúde como resultado das condições econômicas, políticas, sociais e culturais, o trabalho da enfermagem passa a fazer parte do conjunto de profissões necessárias à identificação e análise dos fatores que intervém no processo saúde/doença, promoção e prevenção à saúde. 0 ambiente hospitalar é insalubre e os profissionais estão expostos a diferentes estressores ocupacionais.

Diante dos dados apresentados pode-se perceber que todas as categorias de enfermagem apresentaram fatores preditores a Síndrome de Burnout assim como da patologia. No que refere aos fatores preditores, foram predominantes à falta da valorização e reconhecimento do trabalho desenvolvido, $70,4 \%$ por parte da instituição, a falta de reconhecimento e recompensa $63 \%$, como sendo causa de descontentamento com a profissão e desgaste físico e emocional. Foi relatada ainda a sobrecarga laboral $25,9 \%$, que causa desequilíbrio entre as cobranças de trabalho e o quantitativo dos profissionais, com consequente conflito no trabalho.

Quanto à sintomatologia manifestada pelos profissionais de enfermagem, com uma constância de todos os dias $25,9 \%$ acenaram irritabilidade fácil, sentimento de cansaço mental e pouco tempo para si mesmo. 0 absenteísmo não apareceu como um indicador negativo o que pode dar a entender um compromisso com o trabalho. Quando elencado a resposta dos profissionais, uma parcela significativa replica que suas atividades são importantes quase sempre.

As condições públicas de saúde impõem dificuldades administrativas e gerenciais que lidam, também, com dificuldades de recursos humanos e materiais, sendo para os gestores um enorme desafio mediar situações estressantes e conflitos.
Sugerem-se acolhimentos às relações interpessoais com perfil de liderança participativa no ambiente de trabalho, assim concordando que a dinâmica organizacional do pronto socorro gera uma sobrecarga e tensão ocupacional, é necessário desenvolver táticas de reorganização do processo de trabalho, portanto recomenda-se que o sistema de classificação de risco já em uso nesse hospital possa estar alinhado às necessidades de horas de cuidados de enfermagem o que justificará o quantitativo de profissional ideal para uma assistência de qualidade com consequente melhoria da saúde do trabalhador.

Propõe-se, ainda, que as ações de enfermagem possam ser sistematizadas, com implementação da SAE, protocolos e rotinas e que estas possam ser desenvolvidas com apoio da educação permanente e táticas da gestão. Dessa forma inúmeras vantagens são obtidas, como direcionamento das ações de enfermagem, maior facilidade na passagem de plantão e vantagens principalmente para o paciente por tornar o atendimento de enfermagem personalizado, individualizado, eficiente e eficaz. Por meio desses processos é possível maior integração e interação da enfermagem com o paciente, família, comunidade e com a própria equipe multidisciplinar.

A saúde do trabalhador deve estar atenta às necessidades desse grupo. As instituições devem ser "sensíveis", no sentido de intervir sobre os processos de trabalho com oferta para condições de trabalho, carga horária e remunerações justas, não oponentes as relações de trabalho devem verter a garantir não somente os direitos, mas também os deveres nessas relações, como a reorganização do processo de trabalho em forma de gerenciamento da unidade, por meio de protocolos, fluxogramas e manuais com normas técnicas. 


\section{REFERÊNCIAS}

BALLONE, G. J.; MOURA, E. C. Síndrome de Burnout. 2008. Disponível em: <www.psiqweb. med.br>. Acesso em: 14 fev. 2012.

BENEVIDES-PEREIRA, A. M. T. Burnout: o processo de adoecer pelo trabalho. In: PEREIRA, A. M. T. B (org.). Burnout: quando o trabalho ameaça o bem estar do trabalhador. São Paulo: Casa do Psicólogo, 2002.

BENEVIDES-PEREIRA, A. M. T. Burnout: quando o trabalho ameaça o bem-estar do trabalhador. São Paulo: Casa do Psicólogo, 2002.

BItTEnCOURT, F. Estresse: o mal do século. Revista Psique Ciência \& Vida, n.75, 2012. p.27-31.

BORGES, L. et al. A síndrome de burnout e os valores organizacionais: um estudo comparativo em hospitais universitários. Psicologia: Reflexão e Crítica, 15, 2002. p.189-200.

BRASIL. Ministério da Saúde. Doenças relacionadas ao trabalho: manual de procedimentos para os serviços de saúde. Brasília-DF, 2001.

BRASIL. Ministério da Saúde. HumanizaSUS-acolhimento com avaliação e classificação de risco: um paradigma ético-estético no fazer em saúde. BrasíliaDF, 2004.

CUSHWAY, D. \& TYLER, P. Stress in clinical psychologists. International Journal of Social Psychiatry, 42, 1996. p.141 -149.

FERREIRA, J. M. Requisitos para a competência no exercício das profissões que cuidam da saúde do trabalhador. In: saúde no trabalho: temas básicos para o profissional que cuida da saúde dos trabalhadores. São Paulo: Roca, 2000.
FREUDENBERGER, H. J. Staff Burn-Out. Journal of Social Issues, 30, 1974. p.159-165.

GOVERNO do Estado de São Paulo. Procuradoria Geral do Estado. Estatuto dos Funcionários Públicos Civis do Estado. Lei n. 10.261, de 28 de outubro de 1968. São Paulo: Centro de Estudos, 2004.

GUIMARÃES L. A. M.; CARDOSO, W. L. C. D. Atualizações da síndrome de burnout. São Paulo: Casa do Psicólogo, 2004.

JODAS, D. A.; HADDAD, M. C. L. Síndrome de Burnout em trabalhadores de enfermagem de um pronto Socorro de hospital universitário. Londrina-PR, 2008.

LAUTERT, L. O desgaste profissional: uma revisão da literatura e implicações para a enfermeira. Revista Gaúcha Enfermagem. Porto Alegre, v.18, n.2, jul. 1997. p.83-93.

MASLACH, C. G. J. Prevention of burnout new perpectives. Applied Preventive Psychology. 7: 63-74, 1998.

MASLACH, C.; JACKSON, S. E. The measurement of experienced burnout. Journal of Occupational Behavior, 1981. 2:99-113.

MASLACH, C.; LEITER, M. P. Trabalho: fonte de prazer ou desgaste. Campinas: Papirus, 1997.

MENEGAZ, F. D. L. Características da incidência de Burnout em pediatras de uma organização hospitalar pública. 2004. Dissertação (Mestrado) - Florianópolis: Centro de Filosofia e Ciências Humanas da Universidade Federal de Santa Catarina, 2004.

MUROFUSE, N. T.; ABRANCHES, S. S.; NAPOLEÃO, A. A. Reflexões sobre o estresse e Burnout e a relação com a enfermagem. Rev. Latino-Am. Enfermagem, 2005. 13: 255-261. 
SECRETARIA de Estado da Saúde de Sergipe. Hospital de Urgência de Sergipe Governador João Alves Filho-HUSE. Disponível em: $<w w w . s e s . s e . g o v \cdot b r>$. Acesso em: $10 \mathrm{fev}$. 2012.

http://www.portaldaenfermagem.com.br/estatisticas. Acesso em: 7 jul. 2012. COMPLETAR OU RETIRAR REFERÊNCIA.
TAMAYO, M. R.; TRÓCCOLI, B. T. Burnout no trabalho. In: MENDES, A. M.; BORGES, L. O; FERREIRA, M. C., (Orgs.). Trabalho em transição, saúde em risco. Brasília: UnB/Finateo, 2002.

WORLD HEALTH ORGANIZATION. Guidelines for the primary prevention of mental, neur ological and psychosocial disorders: Staff Burnout. In: Geneva Division of Mental Health Organization, 1998. p.91-110. 